\title{
Effect of the all-trans retinoic acid on neural growth factor serum levels (NGF) and chemotherapy induced neuropathy in patients with advanced lung cancer
}

\author{
Oscar Arrieta*1, Tania Cerón¹, Diana Estrada-Flores¹, Felipe Sánchez¹, \\ Graciela Ordoñez ${ }^{2}$ and Julio Sotelo ${ }^{2}$
}

\author{
Address: ${ }^{1}$ Medical Oncology Department. Instituto Nacional de Cancerologia. Mexico and ${ }^{2}$ Unidad de Neuroinmunología, Instituto Nacional de \\ Neurologia y Neurocirugía. Mexico \\ Email: Oscar Arrieta* - ogar@servidor.unam.mx \\ * Corresponding author
}

from 24 ${ }^{\text {th }}$ Annual Meeting of the National Cancer Institute of Mexico

Mexico City, Mexico. 14-17 February 2007

Published: 5 February 2007

BMC Cancer 2007, 7(SuppI I):A3 I doi:I0.I 186/I47I-2407-7-SI-A3 I

This article is available from: http://www.biomedcentral.com/I47I-2407/7/SI/A3 I

(C) 2007 Arrieta et al; licensee BioMed Central Ltd.

\section{Background}

Peripheral neuropathy is a common adverse event in patients treated with chemotherapy. The development of peripheral neuropathy observed in chemotherapy is similar to the diabetic patients where there is reduction of the expression and transport of Neural Growth Factor (NGF). Retinoic acid (RA) regulates genes related to cellular proliferation and the expression of NGF. Phase 1 and in vitro studies suggested that retinoic acid may synergize the therapeutic effect of chemotherapy, in particular paclitaxel and cisplatin. We conducted a phase II randomized double blind clinical trial to determine the effect of all-trans retinoic acid on the development of chemotherapy induced neuropathy based on the combination of paclitaxel and cisplatin in patients with advanced lung cancer; in addition we analyzed the therapeutic effect of retinoic with chemotherapy.

\section{Methods}

Thirty four patients with advanced Non Small Cell Lung Cancer (NSCLC) were included in this study to receive chemotherapy based on the combination of paclitaxel $175 \mathrm{mg} / \mathrm{m} 2$ and cisplatin $80 \mathrm{mg} / \mathrm{m} 2$ every three weeks. The patients' characteristics were median age of $58.9 \pm 12$ years in the control group and $58.4 \pm 12$ in the RA ( $\mathrm{p}=$ $0.914)$. Prior to chemotherapy and after two cycles of treatment neurophysiology studies, clinical examination and serum NGF levels were performed. The patients were randomized to receive all-trans retinoic acid $20 \mathrm{mg} /$ day or placebo 1 week before treatment and after completing 2 cycles.

\section{Results}

Grade I and II neuropathy was increased in the control group after 2 cycles (2C) of chemotherapy (66\% vs. $24.1 \% \mathrm{p}=0.05)$. NFG serum levels were lower in the placebo group $4.89 \mathrm{pg} / \mathrm{ml}$ baseline and $4.6 \mathrm{pg} / \mathrm{ml} \mathrm{2C}(\mathrm{p}=$ 0.007 ) vs. all-trans retinoic acid $4.8 \mathrm{pg} / \mathrm{ml}$ and $4.7 \mathrm{pg} / \mathrm{ml}$ $(\mathrm{p}=0.107)$. The electrophysiological studies showed that the placebo group had a greater degree of motor axonal damage in the median and tibial nerves. The secondary objective we analyzed response to therapy with differences in response (complete and partial) of $68.4 \%$ in the retinoic acid group vs $26.6 \%$ in the placebo group ( $\mathrm{RR}=$ $2.6 ; 95 \% \mathrm{CI}, 1.1$ to $6.2 ; \mathrm{p}=0.016)$. The disease free survival in the experimental arm was $10.7 \pm 5$ vs. $5.1 \pm 0.8$ months.

\section{Conclusion}

All trans retinoic acid has a neuroprotector effect in patients treated with chemotherapy based on paclitaxel and cisplatin and has activity in global response and in time to disease progression. 